\title{
Clinical outcomes and associated risk factors of Corona Virus Disease 2019 in healthcare workers of KP, Pakistan
}

\author{
Saima Afaq, Wajeeha Qayyum, Muhammad Jawad Zia ul Haq, Muhammad Arsalan, Jalil Khan, \\ Mian Afaq Ahmad, Wagmah Javed Khan
}

Submitted

June 10, 2021

Accepted

July 23, 2021

Author Information

Dr. Saima Afaq

Department of Epidemiology \& Biostatistics, School of Public Health, Imperial College London, UK, \& Institute of Public Health \& Social Sciences, Khyber Medical University, Peshawar, KP, Pakistan

Dr. Wajeeha Qayyum Rehman Medical Institute, Peshawar, KP, Pakistan

Dr. Muhammad Jawad Institute of Public Health \& Social Sciences, Khyber Medical University, Peshawar, KP, Pakistan

(Corresponding Author) Email: mdrjawad@yahoo.com

Dr. Zia ul Haq

Institute of Public Health \& Social Sciences, Khyber Medical University Peshawar, KP, Pakistan

Dr. Muhammad Arsalan Khyber Medical College, Peshawar, KP, Pakistan

\section{Dr. Jalil Khan}

Institute of Public Health \& Social Sciences, Khyber Medical University, Peshawar, KP, Pakistan, \& NHS Bolton, UK

Dr. Mian Afaq Ahmad Institute of Biotechnology \& Genetic Engineering, University of Agriculture, Peshawar, KP, Pakistan

Dr. Wagmah Javed Khan Khyber Girls Medical College, Peshawar, KP, Pakistan

Citation: Afaq S, Qayyum W, Jawad M, ul Haq Z, Arsalan M, Khan J, et al. Clinical outcomes and associated risk factors of Corona Virus Disease 2019 in healthcare workers of KP,

Pakistan. J Rehman Med Inst. 2021 Jul-Sep;7(3):3-8.

\section{ABSTRACT}

Introduction: Khyber Pakhtunkhwa (KP), is geographically the smallest province, characterized by high population growth and a large refugee population. It faces a set of unique obstacles in the health sector including limited human resources, low financial protection, and weak governance.

Objective: To explore clinical outcomes and factors associated with mortality among Health Care Workers (HCWs) of KPK.

Materials \& Methods: It was a cross sectional study conducted over 32 district of KP. A format containing 70 variables, including demographics, comorbidity, symptoms and outcomes, was developed and shared with rapid response teams (RRT) of each district and orientation was given for its use to the teams. Data were collected onto the software IPMS (Integrated Performance Monitoring System). We obtained this information from Health Department KP.

Results: From February 2020 to $27^{\text {th }}$ June 2020,1813 HCWs reported COVID-19 positive; 669 had active infection, 1133 recovered while 11 died. Median age was $34(\mathrm{IQR}=14)$ years, and $76.1 \%$ were males. Fever, cough and sore throat were present in $40.5 \%, 33.5 \%$ and $19.1 \%$ while comorbidity was present in $\sim 2 \%$ of patients. 6 patients were admitted to ICU and 4 patients received invasive ventilation- none survived. After adjusting for potential confounders, age, cough, Shortness of breath (SOB), headache, diabetes and chronic lung disease were significantly associated with mortality (all $\mathrm{p}<0.05$ ).

Conclusion: HCWs, with COVID-19, were young; predominantly males, mostly asymptomatic, and a small proportion had comorbidity. Fever, cough and sore throat were top 3 symptoms. Mortality rate was $0.6 \%$. The outcome was poor in patients who received intensive care/invasive ventilation.

Keywords: Health Personnel; Healthcare Workers; COVID-19; SARS-CoV-2.

The authors declared no conflict of interest. All authors contributed substantially to the planning of research, data collection, data analysis, and write-up of the article, and agreed to be accountable for all aspects of the work.

\section{INTRODUCTION}

Corona virus 2019 (COVID-19) also called SARSCoV-2 hit the world in December 2019 and since then 188 countries have been affected. Almost $18,854,287$ people worldwide have been infected by this contagious virus causing 708,639 deaths globally. ${ }^{1}$ According to a report submitted by World Health Organization (WHO), HCWs have accounted for $21 \%$ cases of COVID-19 globally. ${ }^{2}$

In this challenging time of COVID-19 pandemic, hospitals are getting overloaded with infected patients, both symptomatic and asymptomatic. Patient can shed the virus even in asymptomatic phase of the disease. Human to human transmission is through respiratory droplets. Health care workers are at the front line in attending and managing these patients and transmission to HCWs is known to have occurred. ${ }^{3}$ Due to close proximity and continuous repeated exposure to the contagious virus, HCWs are at an increased risk of acquiring this virus. Moreover, the sudden unpredicted heavy burden of disease and its novelty is the real challenge for healthcare system especially in a resource limited country like Pakistan. ${ }^{3}$ One of the most important routes of secondary transmission of COVID-19 is the spread through a hospital setting. Availability of insufficient accurate data on COVID-19 virulence factors, in vitro survival, incubation, and infectivity period, hindered the planning and implementing of preventive measures for HCWs initially. As a result significant number of HCWs acquired infection and became the source of transmission themselves. ${ }^{3}$

Primary exposure of an $\mathrm{HCW}$ to infected patients before his/her diagnosis is confirmed and work overload during duties are two important risk factors for HCWs getting COVID-19. According to Centres for Disease Control and Prevention (CDC), $9282 \mathrm{HCWs}$ have been affected in the USA, out of which, 55\% had exposure in their place of duty. Furthermore, Temime et al., ${ }^{4}$ described that the risk of COVID-19 infection in HCWs was higher than general population due to their prolonged and close contact with the already infected patients. HCWs who handle patients' airways and/or oral cavity such as dentists, respiratory therapist, anaesthetist and intensivists are at high risk of acquiring the infection. ${ }^{4}$ 
Till date, numerous studies and systemic reviews have highlighted diversity of clinical presentation and severity of COVID-19 infection ranging from being asymptomatic to septic shock and multiorgan dysfunction. ${ }^{5}$ The severity and presentation of disease may vary depending on age group, gender, ethnicity and type of viral strain and viral load..$^{5-7}$ It is assumed that the health care workers are at high risk of getting high viral load due to repeated exposure to COVID-19 infected patients and involvement in aerosol generating procures. ${ }^{3}$ Literature, however, is markedly deficient in elaborating the disease course and outcome in HCWs.

Khyber Pakhtunkhwa (KP) is one of the 4 provinces of Pakistan with a population of 35.53 million $(14.69 \%$ of Pakistan population) supported by 9 teaching Hospitals. In this pandemic, HCWs are affected more in KP as compared to other provinces of Pakistan. ${ }^{8}$

Already published literature revealed that disease transmission is mainly dependent upon exposure and its clinical course and outcome is variable according to host demographics, ethnic background, and available healthcare facilities. Being a resource poor country with distinct ethnicity we may have unique disease pattern and transmission. To date no comprehensive research work focusing on the Indian subcontinent has been published focusing COVID-19 infection in HCWs; moreover, to date no study focusing on this issue has been carried out on such a large scale. Our study can be considered as pioneer study on this topic from Indian subcontinent and unique due to its multicentred nature at global level.

The present study was conducted to explore the clinical outcomes and factors associated with mortality amongst the HCWs of KP, Pakistan.

\section{MATERIALS \& METHODS}

A cross sectional study was conducted on all HCWs infected with COVID-19 across all 32 districts of the KP province from February 2020 to $27^{\text {th }}$ June 2020 . Data about demographics, clinical manifestations, and outcomes of all COVID-19 affected HCWs from the Department of Health Khyber Pakhtunkhwa, Pakistan were obtained. At the beginning of the pandemic, a format containing 70 variables, including demographics, comorbidities, symptoms, and outcomes, was developed by a provincial team led by Additional Director General Health Services (ADGHS) Public Health. It was then shared with Rapid Response Teams (RRT) of each district and orientation was given for its use to the teams. Each district entered their own data onto the software IPMS (Integrated Performance Monitoring System) and shared it with Provincial Data Team daily. Provincial Data Team prepared a daily provincial report and shared it with National Command Operation Centre (NCOC) and other stakeholders. This dataset comprehensively covered updates on surveillance, morbidity, admissions, recoveries \& mortalities.

Request was submitted to the Additional DG Health, Khyber Pakhtunkhwa for the permission to study the provincial COVID19 patient data available at the department. Study protocol was submitted with the request which was examined by the authorities of the department as well as the Ethics Committee of Khyber
Medical University Peshawar, KP and permission was granted. Ethical and administrative permission was obtained. All patient identifiers including names, fathers' names, and CNIC numbers were removed from the dataset.

\section{Statistical analysis}

Data were analyzed using SPSS 23 and STATA 15. Continuous variables are presented as Mean (SD) while categorical variables as frequencies and percentages. Frequencies of demographic characteristics, symptoms and comorbidities were compared between the survivors and non-survivors using the Chi Square and Fisher's exact tests. Binary logistic regression analyses were used to determine the univariate associations of demographic characteristics, symptoms, and co morbidities of the patients with patients' status. Patients' status was defined as recovered or death from the COVID-19 infection. Multivariable logistic regression was conducted with patient status as the outcome. All significant variables in univariate analysis were included in a multivariate logistic regression model with Forward selection method to identify the independent predictors and avoid overfitting of the regression model. Odds ratios (OR) along with their 95\% confidence intervals, [OR $(95 \% \mathrm{CI})]$, were used to quantify the associations between predictors and the outcomes. Sensitivity analysis was performed using the "exact logistic regression" analysis to account for the limited number of death events. The statistical significance level was set at $\mathrm{p}<0.05$ (two-sided).

\section{RESULTS}

From April 01, 2020 to June 27, 2020, 1813 healthcare workers reported as COVID-19 positive from all districts of Khyber Pakhtunkhwa (KP), Pakistan. All these patients had positive laboratory confirmation of SARS-CoV-2 infection. Lab confirmation of infection was done via RT-PCR for SARS Cov2 on nasopharyngeal swab. None of the 1813 patients was lost to follow up. The median (IQR) age was $34 \pm 14$ years and almost half of patients were aged 31-50 years; 1380 (76.1\%) patients were males. Of 1813 patients, 669 had active infection, 1133 recovered, while 11 died as of $27^{\text {th }}$ June 2020. Among the deceased, there were 4 doctors, 4 paramedical staff, 1 nurse, 1 technician and 1 sanitary worker.

Table 1 depicts the demographic and baseline data of the study subjects. There was a male predominance $(76.1 \%)$ and most cases $(49.8 \%)$ were in the age group of 31-50 years. Overall 783 (43.2\%) patients were symptomatic. Fever (40.5\%) was the most common symptom, followed by cough $(33.5 \%)$, and sore throat $(19.1 \%)$. Shortness of breath was present in $5.5 \%$, while headache and diarrhoea were each present in $3 \%$ of the patients. (Table 1).

Approximately $2 \%$ of the patients had comorbidities including cardiovascular disease / hypertension (1\%), chronic lung disease $(0.4 \%)$ and diabetes $(0.9 \%)$. Only 1 patient was pregnant. Regarding the place of management, 1114(61.4\%) patients were home quarantined. A total of 6 patients were admitted to the Intensive care Unit (ICU) and 04(0.2\%) patients received invasive ventilator (Table 1).

Regarding patient status, 1133(62.5\%) recovered, 669(36.9\%) remained active cases, and $11(0.6 \%)$ died (Table 1$)$. 
Table 1. Demographics and baseline characteristics of health care workers with COVID-19 (n=1813).

\begin{tabular}{|c|c|c|c|}
\hline \multicolumn{2}{|c|}{ Demographic \& Baseline Variables } & \multirow{2}{*}{$\begin{array}{c}\text { Frequency } \\
689 \\
902 \\
222\end{array}$} & \multirow{2}{*}{$\begin{array}{c}\text { Percentage } \\
38.0 \\
49.8 \\
12.2\end{array}$} \\
\hline Age (years) & $\begin{array}{l}>=30 \\
31-50 \\
>=51\end{array}$ & & \\
\hline Gender & $\begin{array}{l}\text { Female } \\
\text { Male }\end{array}$ & $\begin{array}{c}433 \\
1380\end{array}$ & $\begin{array}{l}23.9 \\
76.1\end{array}$ \\
\hline $\begin{array}{l}\text { Symptoms } \\
\mathrm{f}=783,43.2 \%\end{array}$ & $\begin{array}{l}\text { Flu } \\
\text { Fever } \\
\text { Sore throat } \\
\text { Cough } \\
\text { Diarrhoea } \\
\text { Shortness of breath } \\
\text { Headache }\end{array}$ & $\begin{array}{c}80 \\
735 \\
347 \\
607 \\
54 \\
100 \\
54\end{array}$ & $\begin{array}{c}4.4 \\
40.5 \\
19.1 \\
33.5 \\
3.0 \\
5.5 \\
3.0\end{array}$ \\
\hline Co morbidities $(n=34,1.9 \%)$ & $\begin{array}{l}\text { Cardiovascular / hypertension } \\
\text { Chronic lung disease } \\
\text { Diabetes } \\
\text { Pregnant }\end{array}$ & $\begin{array}{c}19 \\
7 \\
16 \\
1\end{array}$ & $\begin{array}{c}1.0 \\
0.4 \\
0.9 \\
0.06\end{array}$ \\
\hline Management place & $\begin{array}{l}\text { Home quarantine } \\
\text { ICU }\end{array}$ & $\begin{array}{c}1114 \\
6\end{array}$ & $\begin{array}{c}61.4 \\
0.3\end{array}$ \\
\hline Ventilation & & 4 & 0.2 \\
\hline Patient Status & $\begin{array}{l}\text { Recovered } \\
\text { Died } \\
\text { Active }\end{array}$ & $\begin{array}{c}1133 \\
11 \\
669\end{array}$ & $\begin{array}{c}62.5 \\
0.6 \\
36.9\end{array}$ \\
\hline
\end{tabular}

Table 2 shows comparative analysis of characteristics for survivors and non-survivors. Non-survivors had significantly more patients above age 50 years $(\mathrm{p}<0.001)$. Almost all nonsurvivors $(10 / 11)$ were symptomatic, with fever and cough. Shortness of breath, headache, and sore throat were higher in nonsurvivors (all $p<0.001$ ). Comorbidities were significantly more in non-survivors than in survivors. Out of the 6 patients who were admitted to the ICU, 5 did not survive. None of the survivors had invasive ventilation whereas 4/11(36.4\%) non-survivors received invasive ventilation. All non-survivors were admitted to hospitals, compared to $38.7 \%$ of survivors. Gender and diarrhoea showed non-significant differences.

Table 2. Comparison of demographics and baseline characteristics of survivors and non-survivors (n=1144).

\begin{tabular}{|l|c|c|c|c|c|}
\hline \multirow{2}{*}{ Demographic \& Clinical Values } & \multicolumn{4}{|c|}{ Patient Status } & \multirow{2}{*}{ p value } \\
\cline { 2 - 5 } & \multicolumn{2}{|c|}{ Survivors (n=1133) } & \multicolumn{2}{c|}{ Non-survivors (n=11) } & \\
\cline { 2 - 5 } Age (years) & $\mathrm{f}$ & $\%$ & $\mathrm{f}$ & $\%$ & \\
$>=30$ & 438 & 38.7 & 0 & 0.0 & $<0.001$ \\
$31-50$ & 550 & 48.5 & 3 & 27.3 & \\
$>=51$ & 145 & 12.8 & 8 & 72.7 & \\
\hline Gender & & & & & \\
Female & 248 & 21.9 & 2 & 18.2 & 0.7 \\
Male & 885 & 78.1 & 9 & 81.8 & \\
\hline Symptoms & 442 & 43.3 & 10 & 90.9 & 0.002 \\
Flu & 51 & 4.5 & 1 & 09.1 & 0.40 \\
Fever & 430 & 38.0 & 10 & 90.9 & $<0.001$ \\
Sore throat & 212 & 18.7 & 6 & 54.5 & 0.003 \\
Cough & 356 & 31.4 & 10 & 90.9 & $<0.001$ \\
Diarrhoea & 33 & 2.9 & 1 & 09.1 & 0.20 \\
Shortness of breath & 66 & 5.8 & 5 & 45.5 & $<0.001$ \\
Headache & 28 & 2.5 & 3 & 27.3 & $<0.001$ \\
\hline Comorbidities & 20 & 1.8 & 7 & 63.6 & $<0.001$ \\
Cardiovascular / hypertension & 11 & 1.0 & 4 & 36.4 & $<0.001$ \\
Chronic lung disease & 4 & 0.4 & 2 & 18.2 & $<0.001$ \\
Diabetes & 9 & 0.8 & 4 & 36.4 & $<0.001$ \\
Pregnancy & 1 & 0.1 & 0 & 0.0 & 0.9 \\
\hline Severity & & & & & \\
ICU admission & 1 & 0.1 & 5 & 45.5 & $<0.001$ \\
Ventilator requirement & 0 & 0.0 & 4 & 36.4 & $<0.001$ \\
\hline Quarantine facility & & & & & \\
Hospital / Health facility & 439 & 38.7 & 11 & 100.0 & $<0.001$ \\
Home quarantine & 694 & 61.3 & 0 & 0.0 & $<0.001$ \\
\hline
\end{tabular}


In univariable logistic regression analysis, age, symptoms of fever, sore throat, cough, shortness of breath, and headache, and co morbidities were associated with death (Table 3). The highest OR was obtained for comorbidities (97.38), followed by diabetes (71.36), chronic lung disease (62.72), cardiovascular disease / hypertension (58.29). Lesser factors were cough (21.82), fever
(16.35), headache (14.80), shortness of breath (13.47), and presence of symptoms (13.07).

Similar results were obtained using Exact logistic regression to account for limited number of deaths (non survivors).

Table 3. Univariable logistic regression analysis of factors associated with death among health care workers with COVID-19.

\begin{tabular}{|l|c|c|}
\hline \multicolumn{1}{|c|}{ Variables } & OR (95\% CI) & p value \\
\hline Age & $1.04(1.02-1.06)$ & $<0.001$ \\
\hline Gender & $1.26(0.27-5.87)$ & 0.7 \\
\hline Symptoms & $13.07(1.67-102.53)$ & 0.01 \\
\hline Flu & $2.12(0.26-16.89)$ & 0.5 \\
\hline Fever & $16.35(2.08-128.16)$ & 0.008 \\
\hline Sore throat & $5.21(1.57-17.24)$ & 0.007 \\
\hline Cough & $21.82(2.78-171.15)$ & 0.003 \\
\hline Diarrhoea & $3.33(0.41-26.80)$ & 0.2 \\
\hline Shortness of breath & $13.47(4.01-45.29)$ & $<0.001$ \\
\hline Headache & $14.80(3.73-58.76)$ & $<0.001$ \\
\hline Comorbidities & $97.38(26.39-359.36)$ & $<0.001$ \\
\hline Cardiovascular / hypertension & $58.29(14.89-228.11)$ & $<0.001$ \\
\hline Chronic lung disease & $62.72(10.16-386.99)$ & $<0.001$ \\
\hline Diabetes & $71.36(17.73-287.27)$ & $<0.001$ \\
\hline
\end{tabular}

Multivariable logistic regression was conducted with patient status as the outcome (Table 4), as explained in Materials \& Methods (Statistical analysis). Analysis was conducted separately for symptoms and comorbidities, while age and sex were included in both analyses. Amongst the symptoms, cough, shortness of breath, and headache were included in the adjusted logistic regression analysis. All three factors were significantly associated with higher risk of death $(p=0.009, p=0.04$ and $p=0.04$ respectively). On the other hand, in adjusted logistic regression analysis for the comorbidities, only chronic lung disease $(p=0.001)$ and diabetes $(p<0.001)$ were significantly associated with a higher risk of death. Age was significantly associated with an increase in the risk of death after adjustment of both symptoms and co morbidities (both $p<0.001$ ). Due to the limited number of death events, the OR $(95 \% \mathrm{CI})$ from logistic regression were highly inflated. Therefore, sensitivity analysis was performed using the "exact logistic regression" analysis. However, similar results, with inflated ORs (95\% Cis), were obtained.

Table 4. Multivariable logistic regression analysis of factors associated with death among health care workers with COVID-19.

\begin{tabular}{|l|c|c|}
\hline \multicolumn{1}{|c|}{ Variables } & OR $(\mathbf{9 5 \%}$ CI) & p value \\
\hline Symptoms & $1.088(1.043-1.134)$ & $<0.001$ \\
Age & $92.123(3.143-2700.022)$ & 0.009 \\
Cough & $4.251(1.069-16.903)$ & 0.04 \\
Shortness of breath & $5.317(1.088-25.976)$ & 0.04 \\
Headache & & \\
Comorbidities & $1.046(1.020-1.071)$ & $<0.001$ \\
Age & $47.905(4.783-479.833)$ & 0.001 \\
Chronic lung disease & $50.861(10.892-237.493)$ & $<0.001$ \\
Diabetes &
\end{tabular}

\section{DISCUSSION}

Our results reveal that amongst the total 1813 health care workers, with confirmed COVID-19 from March 01 till June 27, 2020, $0.6 \%$ did not survive, $62.5 \%$ recovered while $36.9 \%$ remained active with the infection. Overall, $43.2 \%$ patients were symptomatic, with fever and cough being the most common symptoms. The majority, 73\% (8/11) non-survivors were aged above 50 years. Almost all non-survivors were symptomatic and had comorbidities, including cardiovascular diseases / hypertension, diabetes and chronic lung disease and were admitted in a hospital. Most, (5/6) patients admitted to the ICU did not survive while none of the patients on invasive ventilation survived. Amongst the symptoms, cough, shortness of breath, and headache, while amongst the comorbidities, chronic lung disease and diabetes, were significantly associated with a higher risk of death. Age was significantly associated with an increase in the risk of death after adjustment of both symptoms and comorbidities. Gender was not associated with increased risk of death.

To date, there are a limited number of publications and national situation reports that provide information on the number of $\mathrm{HCW}$ infections. ${ }^{9}$ Globally, HCWs accounted for $2.5 \%$ of total COVID- 
19 infections in an analysis based on cases reported till $29^{\text {th }}$ March 2020. ${ }^{10}$ However, the tally varies among different countries. A publication from China CDC on 44,672 confirmed cases, as of $17^{\text {th }}$ February 2020, indicated $3.8 \%$ (1688) of the infections were among HCWs. ${ }^{11}$ In Italy, a situation report from 10 April 2020 reported 15,314 infections among $\mathrm{HCW}$, representing $11 \%$ of all infections at that time. ${ }^{12}$ In Spain, HCW infections accounted for $20.4 \%$ of total cases $(23,728 / 116,386)$ reported to the National Centre of Epidemiology on $28^{\text {th }}$ February $2020 .{ }^{10}$ According to the preliminary data released by the CDC, $19 \%(9,282 / 49,370)$ of total infections in the United States were attributed to HCWs. ${ }^{13}$ Our study shows that $7.14 \%$ (1813/25380) health care workers from KP, Pakistan, were infected with COVID-19.

Median age of our study population was 34 years. In literature, most of the studies have described comparatively higher age of HCW affected by COVID-19. Two Studies from Netherland reported mean age of affected HCW as 49 years. ${ }^{15,17}$ However, one study from China has described age of affected HCW as 36.5 years, similar to our results. Our study had a high proportion of male HCWs $(76.1 \%)$. In contrast, studies by Kluytmans-van den Bergh MF et al., ${ }^{15}$ Chou R et al., ${ }^{18}$ Lai X et al., ${ }^{14}$ Sikkema RS et al. ${ }^{17}$ mentioned a higher proportion of female HCWs affected with COVID-19 (83\%, 69\%, $71.8 \%$ and $83 \%$ respectively). The relatively younger age of $\mathrm{HCWs}$ and the predominance of males in our study may be explained by the fact that in this particular setup, frontline doctors and paramedics are usually the early or mid-career males.

In our study population, more than half of the HCWs were asymptomatic. Results from Italy also revealed that around twothird of the HCWs were asymptomatic who tested positive for COVID-19. ${ }^{19}$ The large number of asymptomatic HCW warrants regular screening of them in order to reduce the transmission of disease to patients and their families. Amongst those who were symptomatic, fever was the most common symptoms followed by cough and sore throat. These results are in line with the literature where fever has been identified as the most common symptom universally and cough and sore throat are also included in the top 5 most commonly observed symptoms amongst HCWs infected with COVID-19. ${ }^{14-16}$ Moreover, fever, cough and sore throat are part of clinical criteria set by CDC.

Estimated worldwide mortality is $1.3 \%$ in HCW. ${ }^{18}$ These estimates vary across different regions. According to a review published in June 2020, the highest Case Fatality Rate, 5.7\%, is seen in the Eastern Mediterranean region followed by South East Asia $(3.1 \%)$ while Europe showed the lowest number of deaths $(0.6 \%)){ }^{20}$ In China the COVID-19 related mortality amongst $\mathrm{HCW}$ has been reported as $0.9 \%$ and $0.6 \%$ by Lai $\mathrm{X}$ et al., and Zhan $\mathrm{M}$ et al., ${ }^{14,21} \mathrm{We}$ observed a relatively lower mortality rate of $0.6 \%$ that may be attributed to the younger age and absence of comorbidities in majority of the HCWs. In our study, only $2 \%$ HCWs had comorbidities. Literature search revealed only one study from China presenting the prevalence of comorbidities in HCWs, which included $110 \mathrm{HCWs}$ and the proportion of HCWs with comorbidities was $12.7 \% .{ }^{14}$ Mortality was significantly more in patients aged above 50 years, with comorbidities and symptoms. These findings are supported by a review conducted by Ing et al. ${ }^{22}$ The review reported that older age $>57 \mathrm{yrs}$, male gender (90\% of deaths were male physicians), and pre-existing conditions (hypertension, diabetes mellitus, cardiovascular disease, chronic lung disease, and immunocompromised individuals) were significantly associated with COVID-19 related mortality amongst $\mathrm{HCWs} .^{22}$ In general, older age, male gender and presence of co morbidities are significant risk factors of COVID-19 associated morbidity and mortality. ${ }^{21}$ In contrary to the above mentioned studies, we did not find any gender specific mortality risk in our population. It can be due to racial and ethnic difference but warrants further research work to explore it.

Mortality rate amongst HCWs admitted in ICU was $83.3 \%$ while $100 \%$ patient died who received mechanical ventilation in our study. No study specifically on HCW focused on ICU related mortality, however studies from general population showed higher mortality rates when the pandemic first started (nearly 50$100 \%),{ }^{23,24}$ but as the pandemic advanced, better understanding of the disease and proper channelling of resources led to marked decrease in mortality rate, as described by a systematic review. ${ }^{2}$ ICU related mortality may depend upon healthcare resources, availability of ICU as early as needed, availability of trained and qualified staff, provision of required medication as per need. In $\mathrm{KP}$, only couple of intensivists are available with limited number of ICU beds that too with insufficient facilities, all these factors may have contributed towards the high mortality in patients who received intensive care or invasive ventilation.

This is the first study focusing on HCWs who got infected with COVID-19 from the Indian subcontinent, that too focusing a complete province. Moreover, it is a comprehensive account of demographic features of HCW who suffered from disease and described risk factors of death in them; this again has not been published from this area of the globe. It gave the snapshot of the disease burden on HCW working in a limited resource under developed country. Findings unique to our study are that our COVID-19 affected HCWs were young aged with male predominance, were largely asymptomatic, and only a small proportion suffered from comorbidities. There was no gender specific high rate of death and ICU/ventilator associated mortality was almost $100 \%$.

Our study has some limitations. Firstly, it did not include laboratory or radiological features of the disease, we thus could not categorize patients according to disease severity. Secondly, we could not assess the risk factors in terms of place of duty, working hours, department (COVID unit, aerosol generating procedure etc), and use / provision of PPE. Thirdly, our study is based upon testing the suspected HCWs and as we saw that significant numbers of HCWs were asymptomatic, this means that the disease burden in HCWs is greater than we estimated if results were based upon screening tests but that was not possible on such a large scale due to limited resources. In addition, our results, specifically the ORs obtained through logistic regression, are possibly affected by the "sparse data bias". Limited number of events (11 deaths) in the study population (1813 HCWs) has resulted in inflated ORs with wide confidence intervals. Although sensitivity analysis was performed using "exact logistic regression" analysis, still similar results with high ORs and wide confidence intervals were obtained. 


\section{CONCLUSION}

The HCWs with COVID-19 infection were predominantly young males. More than half of the patients were asymptomatic, and a very small proportion had comorbidities. Fever, cough, and sore throat were top 3 symptoms. Mortality was $0.6 \%$ and death rate was more in patients above 50 years with comorbidities and symptoms. Gender was not associated with a higher risk of mortality. The outcome was poor in patients who received intensive care / invasive ventilation.

\section{REFERENCES}

1. WHO. Novel coronavirus (2019-nCoV) situation reports. [cited 2020 August 7]. Available from: https://www.who.int/emergencies/diseases /novel-coronavirus-2019/situation-reports.

2. Mhango M, Dzobo M, Chitungo I, Dzinamarira. COVID-19 Risk factors among health workers: a rapid review, safety and health at work. Saf Health Work. 2020 Sep;11(3):262-5. doi: 10.1016/j.shaw.2020.06.001.

3. Ali S, Noreen S, Farooq I, Bugshan A, Vohra F. Risk Assessment of Healthcare Workers at the Frontline against COVID19. Pak J Med Sci. 2020;36(COVID19S4):COVID19-S99-S103.

doi: https://doi.org/10.12669/pjms.36.COVID1 9-S4.2790.

4. Temime L, Gustin MP, Duval A, Buetti N, Crepey P, Guillemot D, et al. A conceptual discussion about the basic reproduction number of severe acute respiratory syndrome coronavirus 2 in healthcare settings. Clin Infect Dis. 2021 Jan 1;72(1):141-3.

5. Zhang JJ, Dong X, Cao YY, Yuan YD, Yang YB, Yan YQ, et al. Clinical characteristics of 140 patients infected with SARS-CoV-2 in Wuhan, China. Allergy. 2020 Jul;75(7):1730-41.

6. Joynt GM, Wu WKK. Understanding COVID-19: what does viral RNA load really mean? Lancet Infect Dis. 2020 Jun; 20(6):635-6. doi: $10.1016 /$ S14733099(20)30237-1.

7. Zou L, Ruan F, Huang M, Liang L, Huang $\mathrm{H}$, Hong $\mathrm{Z}$, et al. SARS-CoV-2 viral load in upper respiratory specimens of infected patients. NEJM. 2020 Mar 19;382(12):1177-9.

8. Jamal S. COVID-19: 58 medical workers die fighting coronavirus in Pakistan. July 02, 2020. World Asia. Available https://gulfnews.com. Accessed on $31^{\text {st }}$ August 2020.

9. World Health Organization. Coronavirus disease 2019 (COVID-19): situation report, 82. Available from: https://apps.who.int/iris/handle/10665/331 780.
10. Harrison D, Muradali K, El Sahly H, Bozkurt B, Jneid H. Impact of the SARSCoV-2 pandemic on health-care workers. Hosp Pract (1995). 2020 Oct;48(4):161-4. doi: 10.1080/21548331.2020.1771010.

11. Surveillances V. The epidemiological characteristics of an outbreak of 2019 novel coronavirus diseases (COVID-19) China, 2020. China CDC weekly. 2020;2(8):113-22.

12. COVID-19 Integrated surveillance data in Italy. [webpage]. Available from: https://www.epicentro.iss.it/en/coronaviru s/sars-cov-2-dashboard.

13. Characteristics of Health Care Personnel with COVID-19-United States Feb 12April 9, 2020. MMWR Morb Mortal Wkly Rep. 2020; 69(15):477-81.

14. Lai X, Wang M, Qin C, Tan L, Ran L, Chen D, et al. Coronavirus disease 2019 (COVID-2019) infection among health care workers and implications for prevention measures in a tertiary hospital in Wuhan, China. JAMA Netw Open. 2020 May 1;3(5):e209666. doi: 10.1001/jamanetworkopen.2020.9666.

15. Kluytmans-van Den Bergh MF, Buiting AG, Pas SD, Bentvelsen RG, Van Den Bijllaardt W, Van Oudheusden AJ, et al. Prevalence and clinical presentation of health care workers with symptoms of coronavirus disease 2019 in 2 Dutch hospitals during an early phase of the pandemic. JAMA Netw Open. 2020 May 1;3(5):e209673. 10.1001/jamanetworkopen.2020.9673.

16. Jin YH, Huang Q, Wang YY, Zeng XT, Luo LS, Pan ZY, et al. Perceived infection transmission routes, infection control practices, psychosocial changes, and management of COVID-19 infected healthcare workers in a tertiary acute care hospital in Wuhan: a cross-sectional survey. Mil Med Res. 2020 May 11;7(1):24. doi: 10.1186/s40779-02000254-8.

17. Sikkema RS, Pas SD, Nieuwenhuijse DF, O'Toole Á, Verweij J, van der Linden A, et al. COVID-19 in health-care workers in three hospitals in the south of the
Netherlands: a cross-sectional study. Lancet Infect Dis. 2020 Nov 1;20(11):1273-80.

18. Chou R, Dana T, Buckley DI, Selph S, Fu R, Totten AM. Epidemiology of and risk factors for coronavirus infection in health care workers: a living rapid review. Ann Intern Med. 2020 Jul 21;173(2):120-36.

19. Fusco FM, Pisaturo M, Iodice V Bellopede R, Tambaro O, Parrella G, et al. COVID-19 among healthcare workers in a specialist infectious diseases setting in Naples, Southern Italy: results of a crosssectional surveillance study. J Hosp Infect. 2020;105(4):596-600.

20. Bandyopadhyay S, Baticulon RE, Kadhum M, Alser M, Ojuka DK, Badereddin Y, et al. Infection and mortality of healthcare workers worldwide from COVID-19: a systematic review. BMJ Global Health. 2020 Dec 1;5(12):e003097.

21. Zhan M, Qin Y, Xue X, Zhu S. Death from Covid-19 of 23 health care workers in China. NEJM. 2020 Jun 4;382(23):2267-8

22. Ing EB, Xu AQ, Salimi A, Torun N. Physician deaths from corona virus disease (COVID-19). Occup Med (Lond). 2020 Jul 17;70(5):370-374 doi: 10.1093/occmed/kqaa088

23. Wang Y, Lu X, Li Y, Chen H, Chen T, Su $\mathrm{N}$, et al. Clinical course and outcomes of 344 intensive care patients with COVID19. Am J Resp Crit Care Med. 2020 Jun 1;201(11):1430-4

24. Auld SC, Caridi-Scheible M, Blum JM, Robichaux C, Kraft C, Jacob JT, et al. ICU and ventilator mortality among critically ill adults with COVID-19. Crit Care Med. 2020 Sep;48(9):e799-e804. doi: 10.1097/CCM.0000000000004457.

25. Quah P, Li A, Phua J. Mortality rates of patients with COVID-19 in the intensive care unit: a systematic review of the emerging literature. Crit Care. 2020 Jun 4;24(1):285. doi: 10.1186/s13054-02003006-1. 